\title{
Genome composition of triploid lily cultivars derived from sexual polyploidization of Longiflorum $\times$ Asiatic hybrids (Lilium)
}

\author{
Shujun Zhou • M. S. Ramanna • \\ Richard G. F. Visser · Jaap M. van Tuyl
}

Received: 27 June 2007 / Accepted: 31 July 2007/Published online: 21 August 2007

(C) Springer Science+Business Media B.V. 2007

\begin{abstract}
About 19 cultivars, which had originated from backcrosses between F1 LA (Longiflorum $\times$ Asiatic) hybrids $(2 \mathrm{n}=2 \mathrm{x}=24)$ as female parents and Asiatic cultivars as male parents $(2 n=2 x=24)$, were analyzed with genomic in situ hybridization. 17 of them were triploid $(2 \mathrm{n}=3 \mathrm{x}=36)$, and two aneuploid $(2 n=3 x+1=37)$. The triploid cultivars had resulted from the functional $2 \mathrm{n}$ eggs produced by the female parents (F1 hybrids) because first division restitution (FDR) occurred in their meiosis during megasporogenesis. Similarly, the aneuploid cultivars had originated from viable $2 n+1$ eggs. The extra chromosome in cultivar 041555 or 041572 resulted from one univalent or one half-bivalent which might have lagged behind when the sister chromatids of the other univalents and half-bivalents were segregating during the FDR process in their LA hybrid parents, respectively. That the majority of cultivars possessed recombinant chromosomes showed that intergenomic recombination might play an important role during the selection of the cultivars directly from $\mathrm{BC} 1$ progenies. That five cultivars of the 15 recombinant cultivars only
\end{abstract}

S. Zhou · M. S. Ramanna · R. G. F. Visser ·

J. M. van Tuyl ( $₫)$

Plant Breeding Lab, Wageningen University,

P.O. Box 386, Wageningen 6700 AJ, The Netherlands

e-mail: jaap.vantuyl@wur.nl

S. Zhou

College of Forestry, Shandong Agricultural University,

Taian, Shandong Province 271018, China had reciprocal recombinant chromosomes and 10 cultivars had non-reciprocal recombinant chromosomes indicates that the latter are more important. Because 9 of the 10 non-reciprocal recombinant cultivars possessed substitutions for recombinant segments, it also indicated that such substitutions could be an important source for the genetic variation in the sexual triploid $\mathrm{BC} 1$ progenies. In such cases there was a potential for the expression of the recessive genes of the backcross parent in a nulliplex (aaa) condition in the substituted segments. Genetic variation resulting from such nulliplex loci might have played a role in the selection of some of the cultivars.

Keywords First division restitution (FDR) . In situ hybridization - Indeterminate meiotic restitution (IMR) - Intergenomic recombination · Lilium · Unreduced gametes or $2 \mathrm{n}$ gametes

\section{Introduction}

Interspecific hybrid origin and polyploidy are two common features of some economically important ornamental crops (Van Tuyl and Lim 2003). These trends are observed in the modern cultivars of lily as well. Lily, one of the most important cut flower crops in the Netherlands, belongs to the genus Lilium of the family Liliaceae. In the genus, three groups of closely related species hybrids which form the three groups of lily cultivars, i.e. Longiflorum (L-genome), Asiatic 
(A-genome) and Oriental (O-genome), have been recognized with genomic in situ hybridization (Karlov et al. 1999). In situ hybridization, as a powerful modern cytogenetic tool, has also been used to analyze different genomes in the hybrids in many crops but also some flowers, e.g. Alstroemeria (Kuipers et al. 1997; Zhou et al. 2003), tulips (Marasek et al. 2006) etc.

It is desirable to combine or introgress some horticultural traits from different genomes into one cultivar in lily breeding. However, it is very difficult to obtain F1 interspecific hybrids in Lilium. With cut style method of pollination and embryo rescue techniques, it has been possible to make crosses between different lily species with different genomes. Similar to other interspecific hybrids, nearly all the F1 LA (Longiflorum $\times$ Asiatic) and OA (Oriental $\times$ Asiatic) hybrids are highly sterile. In order to overcome F1-sterility, chromosome doubling was used in lily breeding (Van Tuyl 1989; Van Tuyl et al. 1992). However, chromosome doubling could not contribute much to introgression breeding, because such amphidiploid hybrids usually produce identical 2x-gametes (Ramanna and Jacobsen 2003; Van Tuyl and Lim 2003). On the other hand, $2 \mathrm{n}$ gametes have been shown to be more valuable for polyploidization and introgression breeding in some cases, e.g., Alstroemeria (Ramanna 1992; Ramanna et al. 2003). Interestingly, some F1 interspecific hybrids in Lilium could produce functional $2 \mathrm{n}$ pollen to some extent and this has been used for introgression lily breeding (Van Tuyl et al. 2000, 2002a, b). Intensive cytological analyses on some F1 hybrids and their sexual triploid $\mathrm{BC} 1$ progenies revealed that, the functional $2 \mathrm{n}$ pollen in lily $\mathrm{F} 1$ hybrids results from first division restitution (FDR) and indeterminate meiotic restitution (IMR), and intergenomic recombination occurs during meiosis of their microsporogenesis (Lim et al. 2001b; Barba-Gonzalez et al. 2004, 2005a, b). However, little attention was paid to female gametes produced by F1 LA hybrids or OA hybrids, although such $2 \mathrm{n}$ gametes have been used in lily breeding by the Dutch lily breeding companies in recent years. In order to fill this knowledge gap, 19 cultivars, obtained from Dutch breeding companies, were analyzed with GISH. Because all cultivars were selected from the first generation of backcrosses between diploid F1 LA hybrids $(2 \mathrm{n}=2 \mathrm{x}=24)$ as female parents and Asiatic cultivars $(2 n=2 x=24)$ as male, the karyotypes of the cultivars were analyzed through GISH so that the composition of $2 \mathrm{n}$ eggs could be assessed, and the usefulness of $2 \mathrm{n}$ gametes for generating genetic variation is discussed.

\section{Materials and method}

Plant materials

All 19 cultivars used in this experiment were supplied by the Dutch lily companies: Royal Van Zanten BV and Vletter \& Den Haan BV. They originated from backcrosses in which F1 LA hybrids $(2 \mathrm{n}=2 \mathrm{x}=24)$ were used as female and Asiatic cultivars $(2 n=2 x=24)$ as male. They were grown in the greenhouse of Plant Research International, Wageningen University, The Netherlands, under standard growing conditions.

Chromosome preparation with root tips

Chromosome preparation was made according to the description by Zhou et al. (2003) with little modification. When the young roots growing on stems were about $2 \mathrm{~cm}$ long, 5 root tips in each case were pretreated in $0.7 \mathrm{mM}$ cycloheximide (Sigma, USA) for $6 \mathrm{~h}$ at $4^{\circ} \mathrm{C}$, then, transferred into a fixative which was composed of one part acetic acid and three part ethanol in volume. After the root tips were fixed at $4^{\circ} \mathrm{C}$ for 2 days, the fixative was discarded and $80 \%$ ethanol was added in place of fixative, after which the root tips were stored at $-20^{\circ} \mathrm{C}$ until use.

The root tips were washed for $10 \mathrm{~min}$ each three times with citrate buffer, then, treated with a pectolytic enzyme mix containing $1 \%(\mathrm{w} / \mathrm{v})$ pectolyase Y23 (Seishin Pharma Company, Japan) and 1\% (w/v) cellulase RS (RPI, USA) for about 75 min until the root tips became soft for squashing. One softened root tip was put on a slide and, under an anatomical microscope, the root cap and other unnecessary parts were removed and the meristem part was left on the slide, $16 \mu \mathrm{l} 45 \%$ acetic acid was immediately added and mixed gently with a needle, then, covered with a square clover glass and squashed gently with the thumb. The slide was dipped in liquid nitrogen for about $20 \mathrm{~s}$ after squashing, after which the cover glass was removed with a blade as soon as the slide had been taken out of the nitrogen. Then, the slide 
was put in pure ethanol for $2 \mathrm{~min}$ and, finally, the slide was air dried and stored at $-20^{\circ} \mathrm{C}$ until use.

Genomic in situ hybridization

Probe and block preparation: Total genomic DNA was extracted from the Longiflorum cultivar 'White Fox' and the Asiatic cultivar 'Polyanne' with the CTAB method (Rogers and Bendich 1988). 'White Fox' DNA was sonicated to 1-10 kb fragments and used as probe. 'Polyanne' DNA was autoclaved to 200-600 bp fragments and used as block. The probe DNA was labelled with digoxigenin-11-dUTP by nick translation method according to the manufacturer's instruction (Roche, Germany).

The in situ hybridization procedure consisted of four parts, i.e., chromosome pre-treatment, hybridization, stringent washing and detection. For chromosome pre-treatment, the slides were treated with $100 \mu \mathrm{g} / \mathrm{ml}$ RNase for one hour and $5 \mu \mathrm{g} / \mathrm{ml}$ pepsin for $10 \mathrm{~min}$ at $37^{\circ} \mathrm{C}$, then fixed in $4 \%$ paraformaldehyde for $10 \mathrm{~min}$. After each of these treatments, the slides were washed with $2 \times$ SSC for $5 \mathrm{~min}$ three times, then, the slides were treated for 3 min with $70 \%$, 90\% and $100 \%$ ethanol, respectively, finally, the slides were dried in air at least for $30 \mathrm{~min}$. For hybridization, the hybridization mix contained $50 \%$ formamide, $10 \%$ dextransulphate, $2 \times \mathrm{SSC}, 0.25 \%$ SDS, $0.6-1.5 \mathrm{ng} / \mu \mathrm{l}$ probe and $25-$ $100 \mathrm{ng} / \mu \mathrm{l}$ block DNA. In order to keep the probe and block DNA denatured, the mix was cooled down with ice at least for $5 \mathrm{~min}$ as soon as it was treated at $70^{\circ} \mathrm{C}$ for $10 \mathrm{~min}$; $40 \mu \mathrm{lmix}$ was added to each slide, the slide was covered with a cover glass and denatured at $80^{\circ} \mathrm{C}$ for $5 \mathrm{~min}$, then kept in a $37^{\circ} \mathrm{C}$ humid box overnight. After hybridization, the slides were washed in $2 \times \mathrm{SSC}$ for $15 \mathrm{~min}$ at room temperature, then, stringent washing was followed in $0.1 \times \mathrm{SSC}$ at $42^{\circ} \mathrm{C}$ for $30 \mathrm{~min}$. The probe labelled with dig-11dUTP was detected with the digoxigenin-FITC detection system. The slide was counterstained with $2 \mathrm{ng} / \mu \mathrm{l}$ DAPI. Fluorescence microscopy was used to check the results and photographs were taken with a CCD camera attached to the microscope (Zeiss Axioplan 2 Imaging Photomicroscope, Germany). With this microscope, one kind of fluorescence can be shown in different colours after imaging without changing the information. The contrast of all images was adjusted with Photoshop.

\section{Chromosome classification and karyotyping}

Based on the GISH results and according to Stuart (1947) and Lim et al. (2000, 2001a), chromosome classification and karyotypes were made.

\section{Results}

Chromosome numbers and genome composition of the cultivars

Representative GISH chromosome images of four cultivars, 041553, 041572, 041574 and 041580, are shown in Fig. 1. Based on GISH results, the chromosome number and the genomic composition of all 19 cultivars are summarised in Table 1, and their karyotypes are shown in Fig. 2. All cultivars consisted of L- and A-genomes. $17 \mathrm{BC} 1$ cultivars were triploid $(2 \mathrm{n}=3 \mathrm{x}=36)$ and two aneuploid $(2 \mathrm{n}=3 \mathrm{x}+1=$ 37) (Table 1). All triploid cultivars consisted of 24 Asiatic chromosomes and 12 Longiflorum chromosomes (In the case of recombinant chromosomes, only the centromeres were taken into account). In view of their chromosomal composition, all of them had resulted from FDR $2 n$ eggs produced by the F1 hybrids. Of the two aneuploid cultivars, which had 37 chromosomes, one had an extra Longiflorum chromosome and the other had an extra Asiatic chromosome. Both of them resulted from $2 n+1$ eggs produced by the $\mathrm{F} 1$ hybrids. In these cases, the extra chromosome in 041555 or 041572 originated from one univalent or one half-bivalent which might have lagged behind when the sister chromatids of the other univalents and half-bivalents were segregating during FDR process of their LA hybrids parents, after which $2 n+1$ gametes were formed (Fig. 2f and i: ${ }^{v}$ ).

Intergenomic recombination and crossover events

Among the 19 cultivars, four cultivars did not have any recombinant chromosome (Fig. 2a). For the 15 cultivars, which contained recombinant chromosomes, the recombinations (crossovers) occurred on 
Fig. 1 The representative GISH results of $\mathrm{BC} 1$ cultivars. Yellow or green chromosomes belong to Lgenome, red, purple or grey chromosomes belong to Agenome, because

Longiflorum genomic DNA was used as probe and labelled with FITC and Asiatic DNA as block. The recombinant chromosomes and their breakpoints are marked with arrow heads and letters. They indicate which chromosomes resulted from intergenomic cross-over. Abbreviations are the same as in tables. (a) 041553, (b) 041572, (c) 041574 (the double arrow indicates two arms of one chromosome), and (d) 041580. Bar $=10 \mu \mathrm{m}$
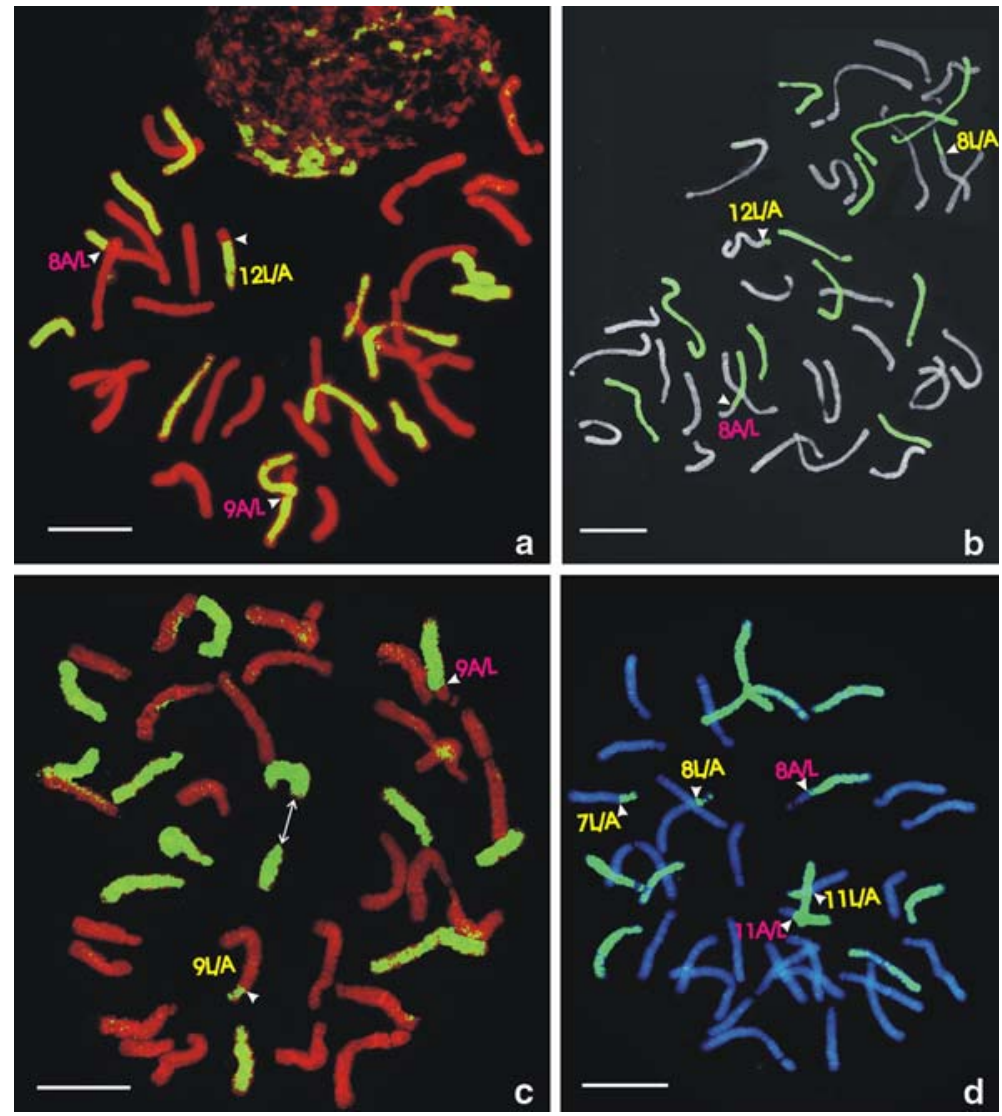

all chromosomes and in each genotype 1-3 pairs of homoeologous chromosomes were involved (Fig. 2 $\mathrm{b}-\mathrm{p}$ and Table 2). When chromosome 1 or 2 (metacentric chromosomes) was the recombinant one, the break point occurred in the long or short arm, whereas when chromosomes 3-12 (acro- or sub-acrocentric chromosomes, i.e., their centromeres are located at or near at one end of the chromosomes) were the recombinant ones (with the exception of chromosome 8 of 041583; Fig. 2p), the break points occurred only on the long arms, and all recombinations were either distal or proximal. Their karyotypes showed that all the recombinant chromosomes probably resulted from a single crossover at pachytene stage during megasporogenesis of the F1 hybrids. When a single crossover occurred within a pair of homoeologous chromosomes (bivalent), the non-sister chromatids originated from the bivalent in its FDR $2 n$ gametes would be non recombinant $(\mathrm{L}, \mathrm{A})$ and reciprocal recombinant (L/A,A/L), or two non reciprocal recombinant (L/A,A and $\mathrm{L}, \mathrm{A} / \mathrm{L}$ ). Apart from the L,A type, which was indistinguishable from the non-crossover FDR 2n gametes, three other types, namely L/A,A/L (Fig. 2: o), L/A,A (Fig. 2: *) and L,A/L (Fig. 2: •) were found in these cultivars. The numbers of these different types were 10,9 and 8 respectively (Table 2 ). In those triploid $\mathrm{BC} 1$ progenies that possessed non-reciprocal products of $\mathrm{L} /$ $\mathrm{A}, \mathrm{A}+\mathrm{A}$, the latter being the chromosome of the backcross parent, there was a substitution for the distal recombinant segment (Fig. 2: *). In these cases, nullipex condition (aaa) can occur and play an important role in genetic variation of such BC1 progenies. On the contrary, such substitutions did not occur when the $\mathrm{L}, \mathrm{A} / \mathrm{L}+\mathrm{A}$ combination was present.

Considering the genome composition of the cultivars, reciprocal recombination could hardly change the genetic information unless the break point(s) would have occurred in a functional gene. The consequence of this kind of recombination should 
Table 1 The genome composition of 19 cultivars (the number of recombinant chromosomes are in brackets)

\begin{tabular}{|c|c|c|c|}
\hline \multirow[t]{2}{*}{ Cultivars } & \multirow{2}{*}{$\begin{array}{l}\text { Chromosome } \\
\text { number }\end{array}$} & \multicolumn{2}{|c|}{ Genome composition } \\
\hline & & $\begin{array}{l}\mathrm{L} \\
(\mathrm{L} / \mathrm{A})\end{array}$ & $\begin{array}{l}\mathrm{A} \\
(\mathrm{A} / \mathrm{L})\end{array}$ \\
\hline 041551 & 36 & $12(1)$ & $24(1)$ \\
\hline 041552 & 36 & $12(2)$ & $24(2)$ \\
\hline 041553 & 36 & $12(1)$ & $24(2)$ \\
\hline 041554 & 36 & $12(1)$ & 24 \\
\hline 041555 & 37 & $12(1)$ & 25 \\
\hline 041568 & 36 & 12 & 24 \\
\hline 041569 & 36 & $12(1)$ & $24(1)$ \\
\hline 041571 & 36 & $12(2)$ & $24(2)$ \\
\hline 041572 & 37 & $13(2)$ & $24(1)$ \\
\hline 041573 & 36 & $12(1)$ & $24(1)$ \\
\hline 041574 & 36 & $12(1)$ & $24(1)$ \\
\hline 041575 & 36 & $12(1)$ & $24(1)$ \\
\hline 041576 & 36 & 12 & 24 \\
\hline 041578 & 36 & $12(1)$ & 24 \\
\hline 041579 & 36 & 12 & 24 \\
\hline 041580 & 36 & $12(3)$ & $24(2)$ \\
\hline 041581 & 36 & 12 & $24(3)$ \\
\hline 041582 & 36 & 12 & 24 \\
\hline 041583 & 36 & $12(1)$ & $24(1)$ \\
\hline
\end{tabular}

$\mathrm{L}=$ Longiflorum chromosome; $\mathrm{A}=$ Asiatic chromosome $\mathrm{A} / \mathrm{L}=$ Asiatic chromosome whose segment was substituted with Longiflorum fragment

L/A = Longiflorum chromosome whose segment was substituted with Asiatic fragment

be almost the same as that of nonrecombination. However, nonreciprocal recombinations could cause genetic variations in $\mathrm{BC} 1$ progenies, especially, when substitution occurred for the recombinant segment. Among the 10 cultivars which contained nonreciprocal recombinants, there were 9 cultivars in which substitution for the recombinant segment was formed. These results imply that this type of nonreciprocal recombinants play a more important role than others.

\section{Discussion}

Mitotic polyploidization by chromosome doubling of the F1 interspecific hybrids contributes little to introgression breeding, however, meiotic polyploidisation induced by $2 \mathrm{n}$ gametes opens a promising way in plant polyploid and introgression breeding (Ramanna and Jacobsen 2003; Van Tuyl and Lim 2003). This point is confirmed by lily polyploid breeding with unreduced female gametes in the present investigation. The previous researches reported that lily F1 interspecific hybrids produce functional unreduced male gametes and the percentage of recombinant triploid $\mathrm{BC} 1$ progenies were $(62.5 \%)$ and $(65.8 \%)$ in ALAs and AOAs, respectively (Lim 2000; Barba-Gonzalez et al. 2005b). The present research showed that F1 LA hybrids could produce functional unreduced female gametes and most cultivars contained recombinant chromosomes. All of these researches confirmed that $2 n$ gametes are very valuable to lily polyploid breeding. Clearly, this is mainly because the genetic variation of $2 n$ gametes caused by intergenomic recombination increases drastically the chances for selecting new cultivars directly from $\mathrm{BC} 1$ population.

Besides intergenomic recombination, mechanism of $2 \mathrm{n}$ gamete formation is another important aspect for sexual polyploidization. The previous researches on $\mathrm{BC} 1$ progenies revealed that the mechanisms of $2 \mathrm{n}$ pollen formed in lily F1 interspecific hybrids are FDR and IMR (Lim et al. 2001b; Barba-Gonzalez et al. 2004, 2005a, b). Numerous examples of FDR 2n gametes produced by $\mathrm{F} 1$ interspecific hybrids have been reported in Aegilops squarrosa $\times$ Triticum durum (Sasakuma and Kihara 1981), emmer wheat $\times$ A. squarrosa (Fukuda and Sakamoto1992), durum wheat $\times A$. squarrosa and rye $\times A$. squarrosa $(\mathrm{Xu}$ and Dong 1992; Xu and Joppa 1995), wheat $\times$ barley (Islam and Shepherd 1980), Alstroemeria interspecific hybrids (Ramanna et al. 2003), and others (Van Tuyl and Lim 2003). In present research, all triploid cultivars resulted from FDR 2 n eggs. Even the two aneuploid cultivars resulted from FDR female gametes with an extra chromosome according to their genome composition. Are FDR gametes more vigorous than IMR gametes, or could the progenies resulting from IMR female gametes be less suitable for selection as cultivars? It is reasonable to assume that the FDR gametes are more vigorous than IMR gametes, because the chromosomal composition of FDR gametes is more balanced than those of IMR gametes. This, however, needs further experimental confirmation.

Two aneuploid cultivars were found in the present investigation which means that some aneuploid eggs 
Fig. 2 The Karyotypes of 19 BC1 cultivars. (a) The four cultivars, which do not have any recombinant chromosome; (b-p) the 15 cultivars which had recombinant chromosomes. In $\mathbf{b}-\mathbf{p}$, only the set (s) of chromosomes that contained substitution of segments or addition of chromosomes are shown. For each set of chromosomes, the pair of chromosomes received from the LA parent is shown at the left and the single chromosome of the backcross parent, i.e., Asiatic cultivar, is shown on the right in each case. Black and grey bars represent Longiflorum and Asiatic chromosomes, respectively
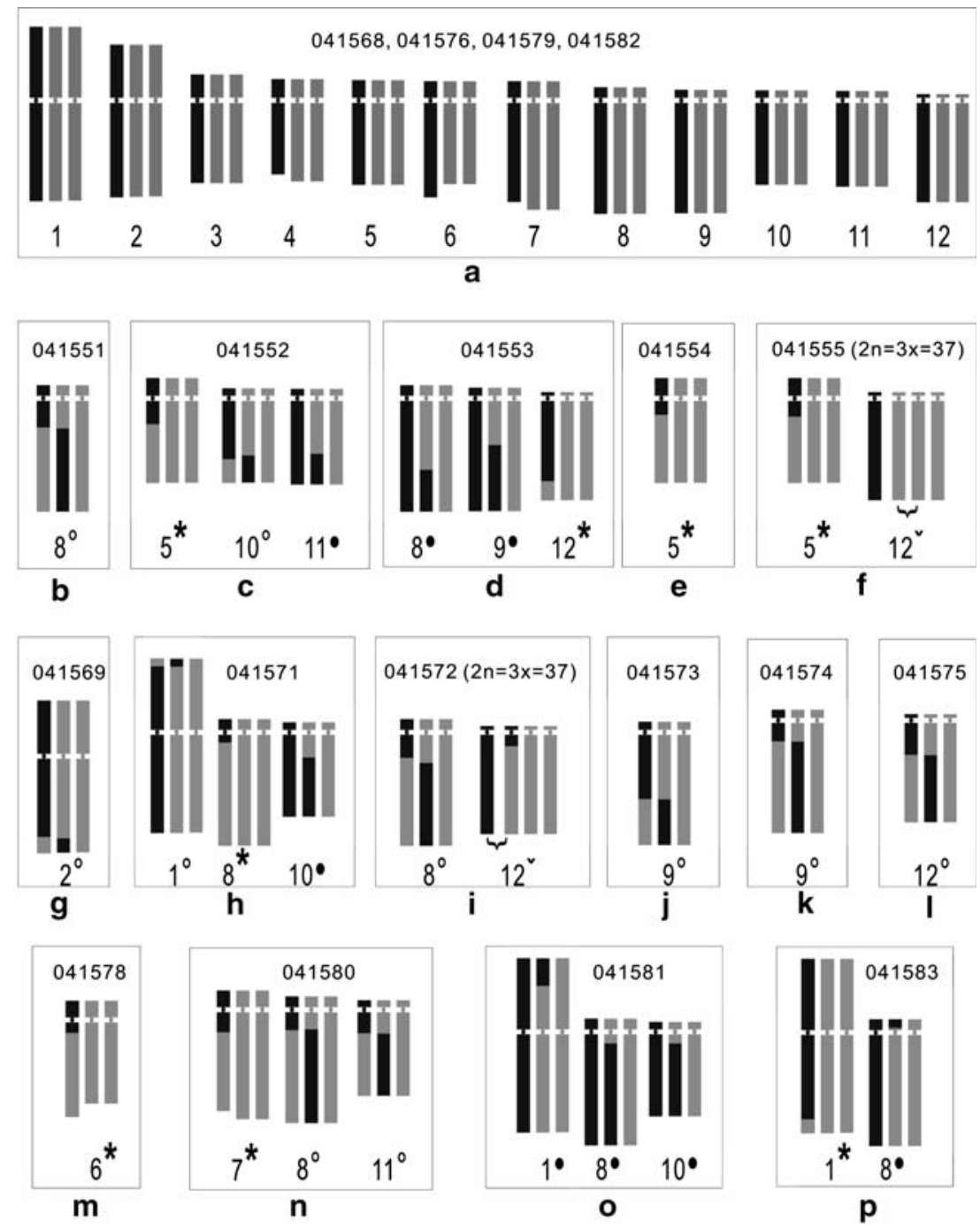

${ }^{\circ}=$ reciprocal recombination

•= nonreciprical recombination and no substitution formed

* = nonreciprical recombination and subsstitution formed

" = chromosomes originated from sister chromatids indicated with "

produced by $\mathrm{F} 1$ LA hybrids could survive in $\mathrm{BC} 1$ progenies. Although LA hybrids have the possibility to produce a large amount aneuploid pollen (Zhou 2007), no aneuploid BC1 progenies of ALA or AOA populations were found in the previous studies (Lim et al. 2001b; Barba-Gonzalez et al. 2004, 2005a, b). Since many cultivars in some of the vegetative propagated crops, e.g. Hyacinthus (Van Scheepen 1991) and Narcissus (Brandham 1992), are aneuploid, it is expected that more and more aneuploid lily cultivars would be selected when interspecific hybrids in Lilium could produce functional aneuploid gametes.
In the mean time, one may not neglect the role of the backcross parent for generating the variation observed in the $\mathrm{BC} 1$ progenies of crosses between LA hybrids and Asiatic cultivars. Out 19 cultivars, in the present investigation, four cultivars did not have any recombinant chromosomes, and five cultivars only had reciprocal recombinant chromosomes. Why could so many of these kinds of $\mathrm{BC} 1$ progenies be selected as cultivars although their genome compositions look the same? Firstly, they originated from different cross combinations. Different Dutch lily companies used different Longiflorum and Asiatic cultivars to obtain different F1 LA hybrids, so, 
Table 2 Status of recombinant chromosomes in 15 cultivars (the classification number of chromosomes is given in brackets)

\begin{tabular}{|c|c|c|c|c|c|}
\hline \multirow[t]{2}{*}{ Cultivars } & \multirow{2}{*}{$\begin{array}{l}\text { No of recombinant } \\
\text { chromosomes }\end{array}$} & \multirow{2}{*}{$\begin{array}{l}\text { No of paired homoeologous } \\
\text { chromosomes }\end{array}$} & \multirow{2}{*}{$\begin{array}{l}\text { Reciprocal product } \\
\text { present } \mathrm{L} / \mathrm{A} ; \mathrm{A} / \mathrm{L}\end{array}$} & \multicolumn{2}{|c|}{ Non reciprocal products } \\
\hline & & & & $\mathrm{L} / \mathrm{A}$ & $\mathrm{A} / \mathrm{L}$ \\
\hline 041551 & 2 & 1 & $1 / 1(8)$ & 0 & 0 \\
\hline 041552 & 4 & 3 & $1 / 1(10)$ & $1(5)$ & $1(11)$ \\
\hline 041553 & 3 & 3 & $0 / 0$ & $1(12)$ & $2(8,9)$ \\
\hline 041554 & 1 & 1 & $0 / 0$ & $1(5)$ & 0 \\
\hline 041555 & 1 & 1 & $0 / 0$ & $1(5)$ & 0 \\
\hline 041569 & 2 & 1 & $1 / 1(2)$ & 0 & 0 \\
\hline 041571 & 4 & 3 & $1 / 1(1)$ & $1(8)$ & $1(10)$ \\
\hline 041572 & 3 & 2 & $1 / 1(8)$ & $1(12)$ & 0 \\
\hline 041573 & 2 & 1 & $1 / 1(9)$ & 0 & 0 \\
\hline 041574 & 2 & 1 & $1 / 1(9)$ & 0 & 0 \\
\hline 041575 & 2 & 1 & $1 / 1(12)$ & 0 & 0 \\
\hline 041578 & 1 & 1 & $0 / 0$ & $1(6)$ & 0 \\
\hline 041580 & 5 & 3 & $2 / 2(7,11)$ & $1(8)$ & 0 \\
\hline 041581 & 3 & 3 & $0 / 0$ & 0 & $3(1,8,10)$ \\
\hline 041583 & 2 & 2 & $0 / 0$ & $1(1)$ & $1(8)$ \\
\hline Total & 37 & 27 & 10 & 9 & 8 \\
\hline
\end{tabular}

Abbreviations are the same as in Table 1

variation must have existed among different F1 LA hybrids, although their karyotypes look the same. Secondly, the fact that Longiflorum and Asiatic cultivars are heterozygous should be considered. Their genetic backgrounds are very complex, especially, Asiatic cultivars originate from crosses among 12 wild species within the Sinomartagon section in Lilium. So, there would be two factors which could cause variation within a $\mathrm{BC} 1 \mathrm{LA}$ population: one factor is the variation of $2 \mathrm{n}$ gametes formed in F1 LA hybrids; the other is chromosome assortment or recombination during $n$ gamete formation in the backcrossing parent 'Asiatic cultivar'. The variation caused by $2 \mathrm{n}$ gametes produced by F1 LA hybrids can be directly detected by the GISH technique. However, it is also expected that chromosome assortment or recombination during haploid gamete formation of Asiatic cultivar could result in variation within its BC1 population, although the variation could not be detected at chromosome level with GISH. When no recombination had occurred in $2 \mathrm{n}$ gametes, the chromosome assortment or recombination during $\mathrm{n}$ gamete formation in the backcrossing parent would be the only factor which caused variation within one $\mathrm{BC} 1$ population.
Indeed, chromosome doubling play hardly role in introgression breeding. However, it is important for ployploid breeding, and if F1 hybrid could not produce some amount of $2 \mathrm{n}$ gametes, chromosome doubling is necessary to overcome F1 sterility for polyploid breeding. This technique has successfully been used for polyploidy breeding in numerous ornamental crops, e.g., Iris (Van Eijk and Eikelboom 1990), Narcissus, Nerine, Lilium, Tagetes, etc. (Van Tuyl and Lim 2003).

Some examples of $\mathrm{n}$ gametes produced by $\mathrm{F} 1$ interspecific hybrids have been observed in Allium cepa $\times$ A. fistulosum (Emsweller and Jones 1945; Khrustaleva and Kik 2000), Alstroemeria aurea $\times$ A. inodora (Kamstra et al. 1999). Since fertile haploid gametes with homoeologous recombination are ideal for introgression breeding without increasing the ploidy level of the following generation, it would be valuable for lily introgression breeding if any such kind of F1 LA interspecific hybrids could be found.

Acknowledgements Authors thank the financial support from National Natural Science Foundation of China (NSFC No.30471222) and the Dutch lily breeding companies (De Jong Lelies BV, Royal Van Zanten BV, Vletter \& Den Haan BV, Testcentrum BV, World Breeding BV and Mak Breeding BV). 


\section{References}

Barba-Gonzalez R, Lim KB, Ramanna MS, Van Tuyl JM (2005a) Use of $2 n$ gametes for inducing intergenomic recombination in lily hybrids. Acta Hortic 673:161-166

Barba-Gonzalez R, Lim KB, Ramanna MS, Visser RGF, Van Tuyl JM (2005b) The occurrence of intergenomic recombination in the F1 hybrids of Oriental $\times$ Asiatic lily hybrids (Lilium) and its significance for genetic variation in the $\mathrm{BC} 1$ progenies as revealed by GISH and FISH analyses. Genome 48:884-894

Barba-Gonzalez R, Lokker BH, Lim KB, Ramanna MS, Van Tuyl JM (2004) Use of $2 n$ gametes for the production of sexual polyploids from sterile Oriental $\times$ Asiatic hybrids of lilies (Lilium). Theor Appl Genet 109:1125-1132

Brandham PE (1992) Chromosome numbers in Narcissus cultivars and their significance to the plant breeder. Plantsman 14:133-168

Emsweller SL, Jones HA (1945) Further studies on the chiasmata of the Allium cepa $\times$ A. fistulosum hybrids and its derivatives. Am J Bot 32:370-379

Fukuda K, Sakamoto S (1992) Cytological studies on unreduced male gamete formation in hybrids between tetraploid emmer wheats and Aegilops squarrosa. Jpn J Breed 42:255-266

Islam AKMR, Shepherd KW (1980) Meiotic restitution in wheat-barley hybrids. Chromosoma 78:363-372

Kamstra SA, Ramanna MS, De Jeu MJ, Kuipers AGJ, Jacobsen E (1999) Homoeologous chromosome pairing in the distant hybrid Alstroemeria aurea $\times A$. inodora and the genome composition of its backcross derivatives determined by fluorescence in situ hybridization with speciesspecific probes. Heredity 82:69-78

Karlov GI, Khrustaleva LI, Lim KB, Van Tuyl JM (1999) Homoeologous recombination in 2 -gamete producing interspecific hybrids of Lilium (Liliaceae) studied by genomic in situ hybridization (GISH). Genome 42:681686

Khrustaleva LI, Kik C (2000) Introgression of Allium fistulosum into A. cepa mediated by A. roylei. Theor Appl Genet 100:17-26

Kuipers AGJ, Van Os DPM, De Jong JH, Ramanna MS (1997) Molecular cytogenetics of Alstroemeria: identification of parental genomes in interspecific hybrids and characterization of repetitive DNA families in constitutive heterochromatin. Chromosome Res 5:31-39

Lim KB (2000) Introgression breeding through interspecific polyploidisation in lily: a molecular cytogenetic study. PhD-thesis, Wageningen University and Research Centre, The Netherlands, $120 \mathrm{pp}$

Lim KB, Chung JD, Van Kronenburg BCE, Ramanna MS, De Jong JH, Van Tuyl JM (2000) Introgression of Lilium rubellum Baker chromosomes into L. longiflorum Thunb-a genome painting study of the $\mathrm{F} 1$ hybrid, $\mathrm{BC} 1$ and $\mathrm{BC} 2$ progenies. Chromosome Res 8:119-125

Lim KB, Wennekes J, De Jong JH, Jacobsen E, Van Tuyl JM (2001a) Karyotype analysis of Lilium longiflorum Thunb and Lilium rubellum Baker by chromosome banding and fluorescence in situ hybridisation. Genome 44:911-918
Lim KB, Ramanna MS, De Jong JH, Jacobsen E, Van Tuyl JM (2001b) Indeterminate restitution (IMR): a novel type of meiotic nuclear restitution mechanism detected in interspecific lily hybrids by GISH. Theor Appl Genet 103:219230

Marasek A, Mizuochi H, Okazaki K (2006) The origin of Darwin hybrid tulips analyzed by flow cytometry, karyotype analyses and genomic in situ hybridization. Euphytica 151:279-290

Ramanna MS (1992) The role of sexual polyploidisation in the origins of horticultural crops: Alstroemeria as an example. In: Mariani A, Tavoletti S (eds) Proceedings of Workshop: Gametes with Somatic Chromosome Number in the Evolution and Breeding of Polyploid Polysomic Species: Achievements and Perspectives, Tipolitografia Porziuncola-Assisi (PG) Italy, pp 83-89

Ramanna MS, Jacobsen E (2003) Relevance of sexual polyploidization for crop improvement-a review. Euphytica 133:3-18

Ramanna MS, Kuipers AGJ, Jacobsen E (2003) Occurrence of numerically unreduced (2n) gametes in Alstroemeria interspecific hybrids and their significance for sexual polyploidisation. Euphytica 133:95-106

Rogers SO, Bendich AJ (1988) Extraction of DNA from plant tissues. In: Gelvin SB, Schiperoort RA (eds) Plant molecular biology manual. Kluwer Academic Publishers, Dordrecht, the Netherlands, pp 1-11

Sasakuma T, Kihara H (1981) A synthesized common wheat obtained from a triploid hybrid, Aegilops squarrosa var. strangulata $\times$ Triticum durum. Wheat Info Serv 52:14-18

Stuart RN (1947) The morphology of somatic chromosomes in Lilium. Am J Bot 34:9-26

Van Eijk JP, Eikelboom W (1990) Prospects for interspecific crosses in Dutch iris. Acta Hort 266:353-356

Van Scheepen J (1991) International checklist for hyacinths and miscellaneous bulbs. Royal General Bulbgrowers Association, Hillegom, The Netherlands

Van Tuyl JM (1989) Research on mitotic and meiotic polyploidisation in lily breeding. Herbertia 45:97-103

Van Tuyl JM, Lim KB (2003) Interspecific hybridization and polyploidization as tools in ornamental plant breeding. Acta Hortic 612:13-22

Van Tuyl JM, Lim KB, Ramanna MS (2002a) Interspecific hybridization and introgression. In Vainstein A (ed) Breeding for ornamentals: classical and molecular approaches. Kluwer Academic Publishers, Dordrecht, The Netherlands, pp 85-103

Van Tuyl JM, Maas IWGM, Lim KB (2002b) Introgression in interspecific hybrids of lily. Acta Hortic 570:213-218

Van Tuyl JM, Meijer H, Van Diën MP (1992) The use of oryzalin as an alternative for colchicine in in-vitro chromosome doubling of Lilium and Nerine. Acta Hortic 325:625-630

Van Tuyl JM, Van Dijken A, Chi HS, Lim KB, Villemoes S, Van Kronenburg BCE (2000) Breakthroughs in interspecific hybridization of lily. Acta Hortic 508:83-88

Xu S, Dong Y (1992) Fertility and meiotic mechanisms of hybrids between chromosome auto duplication tetraploid wheats and Aegilops species. Genome 35:379-374 
Xu S, Joppa LR (1995) Mechanisms and inheritance of first division restitution in hybrids of wheat, rye and Aegilops squarrosa. Genome 38:607-615

Zhou S (2007) Intergenomic recombination and introgression breeding in Longiflorum $\times$ Asiatic lilies. $\mathrm{PhD}$ thesis, Wageningen University and Research Centre, The Netherlands, $111 \mathrm{pp}$
Zhou S, De Jeu MJ, Visser RGF, Kuipers AGJ (2003) Characterisation of distant Alstroemeria hybrids: application of highly repetitive DNA sequences from A. ligtu ssp. ligtu. Ann Appl Biol 142:277-283 